
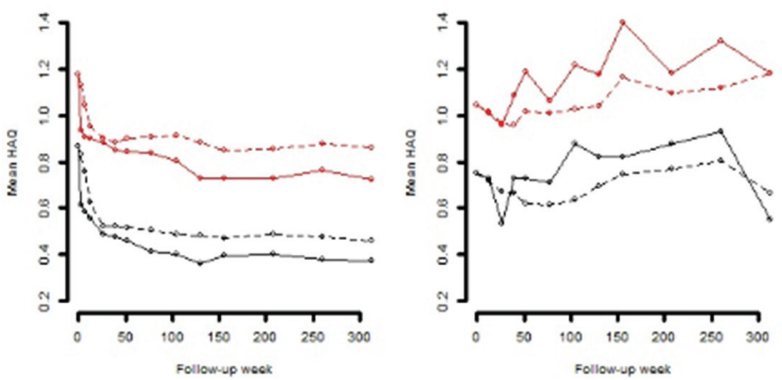

Conclusions: In PsA, across independent European cohorts, HAQ is higher for women, and significantly decreases for both genders when anti-inflammatory treatment is initiated. HAQ does not depend on CRP, VAS-pain or disease duration during longitudinal follow-up. However, a significant increasing trend was identified with ageing

Acknowledgements: This study was supported by unrestricted grants from The Oak foundation, and NordForsk.

Disclosure of Interest: L. E. Kristensen Speakers bureau: Pfizer, AbbVie, Amgen, UCB, Celgene, BMS, MSD, Novartis, Eli Lilly, Janssen Pharmaceuticals, T. S. Jørgensen Speakers bureau: Abbvie, Roche, UCB, Novartis, Pfizer, Biogen and Eli Lilly, L. Coates: None declared, P. Frederiksen: None declared, B. Gudbjornsson: None declared, J. Wallman Consultant for: AbbVie, Celgene, Eli Lilly, Novartis, UCB, N. McHugh Grant/research support from: Pfizer, Celgene and Abbvie, Speakers bureau: Eli Lily, Pfizer and Abbvie, M. Kapetanovic: None declared, L. Dreyer Speakers bureau: UCB, MSD, Janssen, W. Tillett Speakers bureau: Abbvie, Celgene, Eli Lilly, Janssen, Novartis, Pfizer, UCB

DOI: 10.1136/annrheumdis-2018-eular.2908

\section{THU0285 THE EFFECT OF FAMILY HISTORY ON DISEASE PHENOTYPES IN 1393 PSORIATIC ARTHRITIS PATIENTS}

D. Solmaz ${ }^{1}$, S.B. Ureyen ${ }^{1}$, G. Kimyon ${ }^{2}$, E.K. Gunal ${ }^{3}$, A. Dogru', O. Bayindir ${ }^{5}$ E. Dalkilic ${ }^{6}$, C. Ozisler ${ }^{7}$, M. Can ${ }^{3}$, S. Akar ${ }^{5}$, G.Y. Cetin ${ }^{8}$, S. Yavuz ${ }^{3}$, L. Kilic ${ }^{3}$, E. F. Tarhan ${ }^{5}$, O. Kucuksahin ${ }^{7}$, A. Omma ${ }^{7}$, E. Gonullu ${ }^{9}$, F. Yildiz ${ }^{10}$, E.D. Ersozlu ${ }^{11}$,

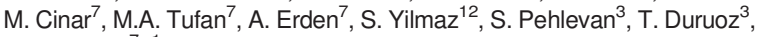
U. Kalyoncu', ${ }^{1}$ S.Z. Aydin, on behalf of PsArt-ID (Psoriatic Arthritis-International Database). ${ }^{1}$ PsArt-ID, Ottawa, Canada; ${ }^{2}$ PsArt-ID, Gaziantep; ${ }^{3}$ PsArt-ID, Istanbul; ${ }^{4}$ PsArt-ID, Isparta; ${ }^{5}$ PsArt-ID, Izmir, ${ }^{6}$ PsArt-ID, Bursa; ${ }^{7}$ PsArt-ID, Ankara; ${ }^{8}$ PsArt-ID, Kahramanmaras; ${ }^{9}$ PsArt-ID, Eskisehir, ${ }^{10}$ PsArt-ID, Van; ${ }^{11}$ PsArt-ID, Adana;

${ }^{12}$ PsArt-ID, Konya, Turkey

Background: Psoriatic arthritis (PsA) has a genetic background, approximately $40 \%$ of patients having a family history of psoriasis or PsA in first-degree relatives, which may impact the disease features.

Objectives: The aim of this study was to evaluate the effects of family history of psoriasis or PsA on the disease phenotypes.

Methods: The demographic and clinical data were retrieved from the longitudinal, multicenter PsArt-ID (Psoriatic Arthritis-International Database). Family history of psoriasis and PsA were investigated for 1 st and 2nd degree relatives separately. The effect of the family history of psoriasis and/or PsA on disease phenotypes and severity were analysed, calculating the relative risks (RR)

Results: 1393 patients had the data for family history, $444(31.9 \%)$ of whom was positive for psoriasis and/or PsA. The majority of the family history was only psoriasis $(333 / 444 ; 75 \%)$ and $58.5 \%$ (260/444) of the patients had first-degree relatives affected. There was no differences in maternal or parental transmission rates however women had more psoriasis and/or PsA in their family $67.3 \%$ vs $32.7 \%$ p: 0.028 ). Patients with a family history had an earlier onset of age for psoriasis $(29 \pm 14.8$ vs $31 \pm 14.9 \mathrm{p:}$ : 0.007$)$, more frequent nail involvement $(50.7 \%$ vs $29.6 \%$ p: 0.032$)$, more frequent enthesitis ( $28.2 \%$ vs $17.7 \%$ p $<0.001)$ and deformities $(25.2 \%$ vs $19.9 \%$ p: 0.05$)$ and were able to achieve minimal disease activity (MDA) less often. (38.6\% vs $49.5 \%$ p: 0.045$)$. Plaque psoriasis was more common if the family history was positive for psoriasis whereas pustular psoriasis was more frequent when the family history was positive for PsA (figure 1). Family history of psoriasis were found as a risk factor for a younger onset (RR: 1.138), for nail disease (RR: 1.179), for enthesitis (RR: 1.504) and for not achieving MDA (RR: 1.246) whereas family history of PsA was a risk factor for having deformities (RR: 1.215) (table 1).
Abstract THU0285 - Table 1. Relative Risks in patients with or without family history of psoriasis or PsA

\begin{tabular}{lcccc}
\hline & $\begin{array}{c}\text { Family } \\
\text { history }\end{array}$ & $\mathrm{p}$ & $\mathrm{RR}$ & $95 \% \mathrm{Cl}$ \\
\hline $\begin{array}{l}\text { Onset of psoriasis before } 40 \text { years } \\
\text { age }\end{array}$ & Psoriasis & $<0.05$ & $\mathbf{1 . 1 3 8}$ & $\mathbf{1 . 0 6 3 -}$ \\
& & & & $\mathbf{1 . 2 1 9}$ \\
& PsA & $>0.05$ & 1.023 & $0.879-$ \\
Nail involvement (ever) & & & 1.191 \\
& Psoriasis & $<0.05$ & $\mathbf{1 . 1 7 9}$ & $\mathbf{1 . 0 4 - 1 . 3 3 5}$ \\
& PsA & $>0.05$ & 1.157 & $0.917-$ \\
Enhesitis (ever) & & & 1.461 \\
& Psoriasis & $<0.05$ & $\mathbf{1 . 5 0 4}$ & $\mathbf{1 . 1 9 2 -}$ \\
& & & $\mathbf{1 . 8 9 8}$ \\
Not achieving MDA & PsA & $>0.05$ & 1.350 & $0.871-$ \\
& & & 2.092 \\
& Psoriasis & $<0.05$ & $\mathbf{1 . 2 4 6}$ & $\mathbf{1 . 0 0 3 -}$ \\
& & & & $\mathbf{1 . 5 4 7}$ \\
Presence of deformities & PsA & $>0.05$ & 1.044 & $0.655-$ \\
& & & & 1.666 \\
& Psoriasis & $>0.05$ & 1.215 & $0.928-$ \\
& & & & 1.592 \\
& PsA & $<0.05$ & $\mathbf{1 . 7 8 6}$ & $\mathbf{1 . 1 7 0 -}$ \\
& & & & $\mathbf{2 . 7 2 7}$ \\
\hline
\end{tabular}

PsA: Psoriatic Arthritis; MDA: Minimal Disease Activity

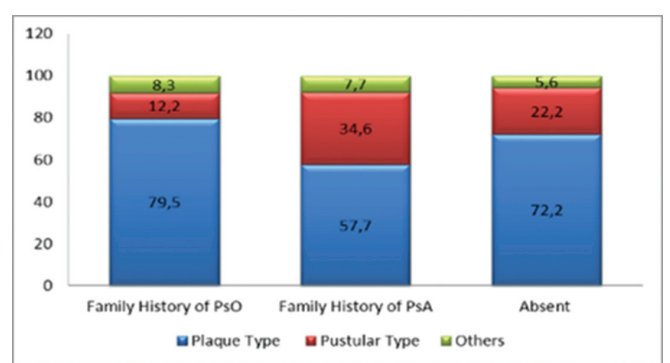

Figure: Distribution of skin lesions according to the family history in patients with PsA. Numbers are given as percentages. PsO: Psoriasis; PsA: Psoriatic Arthritis

Conclusions: The family history of psoriasis and PsA has impacts on skin phenotypes, musculoskeletal features and the disease severity. The differences between family history of psoriasis and PsA and pustular vs plaque phenotypes may point out to a different genetic background and pathogenic mechanisms in these subsets.

Disclosure of Interest: None declared

DOI: 10.1136/annrheumdis-2018-eular.2357

\section{THU0286 PREDICTORS FOR ORTHOPAEDIC SURGERY IN PATIENTS WITH PSORIATIC ARTHRITIS. RESULTS FROM A RETROSPECTIVE COHORT STUDY OF 590 PATIENTS DIAGNOSED 1954-2011, AND FOLLOWED UP UNTIL 2017}

${ }^{1,2}$ T.W. Nystad, Y. Husum ${ }^{1}$, O.N. Furnes ${ }^{2,3}$, B.T.S. Fevang ${ }^{1,2,4} .{ }^{1}$ Bergen group of Epidemiology and Biomarkers in Rheumatic Disease, Department of Rheumatology; ${ }^{2}$ The Norwegian Arthoplasty Register, Department of Orthopaedic surgery, Haukeland University Hospital; ${ }^{3}$ Department of Clinical Medicine;

${ }^{4}$ Department of Clinical Science, University of Bergen, Bergen, Norway

Background: Psoriatic arthritis with peripheral joint affection is a progressive dis ease in most patients, and erosions are seen in $47 \%$ within the first two years. Synthetic disease modifying anti rheumatic drugs (DMARDs) are generally prescribed, to inhibit inflammation, but have not been proven to slow or prevent radiographic changes. Biologic treatment is recommended when other agents are not efficient, and has been shown to give better control of structural damage. ${ }^{2}$

Orthopaedic corrective surgery has been a necessary part of treating patients with psoriatic arthritis, when medication fails to prevent joint destruction. Surgery can be considered a proxy for joint damage, and studying time trends in orthopaedic surgery thus gives valuable information regarding the prognosis of patients with inflammatory arthritis. In patients with rheumatoid arthritis there has, over time, been a declining incidence of orthopaedic interventions. The change in available medical treatment is believed to be responsible for this. ${ }^{3}$ As synthetic 